\title{
Effects of crystalline menthol on blood metabolites in Holstein steers and in vitro volatile fatty acid and gas production ${ }^{1}$
}

\author{
C. L. Van Bibber-Krueger,* K. A. Miller,* \\ C. C. Aperce, $*$ C. A. Alvarado-Gilis, $*$ J. J. Higgins, $\dagger$ and J. S. Drouillard ${ }^{2}$ \\ *Department of Animal Sciences and Industry, Kansas State University, Manhattan 66506; \\ and $\dagger$ Department of Statistics, Kansas State University, Manhattan 66506
}

\begin{abstract}
Fifty-two Holstein steers $(573 \pm 9.92 \mathrm{~kg}$ $\mathrm{BW}$ ) were used to determine if oral administration of crystalline menthol would induce changes in endogenous secretions of IGF-1 and circulating concentrations of glucose, lactate, and plasma urea nitrogen (PUN). Steers were blocked by BW and assigned within block to treatment. Treatments consisted of $0,0.003,0.03$, or $0.3 \%$ crystalline menthol (DM basis) added to the diet. Animals were housed in individual, partially covered pens equipped with feed bunks and automatic water fountains. On d 1 of the experiment, blood samples were obtained via jugular venipuncture at $0,6,12,18$, and $24 \mathrm{~h}$ after feeding. Treatment administration commenced on $\mathrm{d} 2$, and blood samples were again drawn at $0,6,12,18$, and $24 \mathrm{~h}$ after feeding. This bloodsampling schedule was repeated on $\mathrm{d} 9,16,23$, and 30. Plasma was analyzed for PUN, glucose, and lactate concentrations. Serum was used to analyze IGF-1 concentration. Body weights were measured on d 1, 9, 16,23 , and 30 . To accompany the live animal phase, in vitro fermentations were performed using ruminal fluid cultures. Measurements included VFA concentrations and fermentative gas production for cultures containing crystalline menthol at $0,0.003,0.03$, or $0.3 \%$ of
\end{abstract}

substrate DM. Addition of menthol to the diet of steers resulted in a treatment $\times$ day interaction $(P<0.01)$ for concentrations of IGF-1, PUN, and plasma glucose. Cattle fed 0 and $0.003 \%$ menthol had greater serum IGF1 concentrations on $\mathrm{d} 2$ compared with steers fed $0.03 \%$ menthol. Steers fed $0 \%$ menthol had greater serum IGF-1 concentrations on d 9 compared with steers fed 0.03 and $0.3 \%$ menthol, whereas no differences were observed on d 23 or 30. Plasma glucose was similar among treatments until d 23, when steers supplemented with $0.03 \%$ menthol had lower glucose concentrations. Plasma urea nitrogen concentrations were not different among treatments; however, PUN concentrations varied by day. A linear response was detected for BW ( $P=0.03$ ), with steers consuming $0 \%$ menthol having the greatest BW and steers that consumed $0.3 \%$ menthol having the lightest BW until d 30. A menthol $\times$ day interaction was observed for daily feed deliveries $(P<$ 0.01 ): cattle fed $0.3 \%$ menthol consumed less feed from d 5 through 12. Furthermore, in vitro gas production and VFA concentrations were unaffected by addition of menthol $(P>0.21)$. In conclusion, menthol supplementation minimally affected blood parameters associated with growth or ruminal fermentative activity.

Key words: insulin-like glucose factor 1, menthol, plasma urea nitrogen, ruminant

(C) 2016 American Society of Animal Science. All rights reserved.

J. Anim. Sci. 2016.94:1170-1178 doi:10.2527/jas2015-8779

\section{INTRODUCTION}

Menthol is a naturally occurring compound classified as an essential oil that gives plants of the Mentha

\footnotetext{
${ }^{1}$ This is contribution number $15-078-\mathrm{J}$ from the Kansas Agricultural Experiment Station.

${ }^{2}$ Corresponding author: jdrouill@ksu.edu

Received December 3, 2014.

Accepted January 12, 2016.
}

species their characteristic minty aroma and flavor and has been found to have a wide range of biological activities within the body (Eccles, 1994). Menthol has been observed to directly affect $\kappa$-opioid receptors (Galeotti et al., 2002) located in the central nervous system, with a high density found in the hypothalamus (Meng et al., 1993). It was hypothesized that menthol may be capable of binding to $\kappa$-opioid receptors in the hypothalamus, stimulating neuropeptides involved in the production and release of $\mathrm{GH}$ and thus increasing growth. 
Menthol and other essential oils have been studied as potential alternatives to feed antibiotics and growth promotants for livestock (Hosoda et al., 2005; Soltan, 2009; Soltan et al., 2010). In a preliminary experiment using crossbred beef cattle, improvements in growth and increases in circulating concentrations of IGF-1 were observed with short-term oral administration of crystalline menthol (G. L. Parsons and J. S. Drouillard, Kansas State University, Manhattan, KS, personal communication). In addition, menthol is primarily responsible for the antimicrobial properties of peppermint (Ișcan et al., 2002), potentially affecting the rumen microbial population in finishing cattle. The main goal was to assess the underlying changes in metabolism with addition of menthol to the diets of finishing cattle and its effects on in vitro rumen fermentation. It was hypothesized that menthol would increase concentrations of IGF-1 and reduce components related to muscle metabolism (plasma urea nitrogen [PUN], glucose, and lactate) and that increased concentrations of menthol would reduce ruminal fermentation in vitro. Therefore, the objectives of this experiment were to evaluate changes in IGF-1, PUN, glucose, and lactate concentrations when menthol was incorporated into the diets of finishing steers and to assess changes in ruminal gas and VFA production in vitro.

\section{MATERIALS AND METHODS}

Protocols and procedures followed in this study were approved by the Kansas State University Institutional Animal Care and Use Committee.

\section{Experimental Design and Animal Housing}

Fifty-two Holstein steers $(573 \pm 9.92 \mathrm{~kg})$ approximately 17 mo of age were used in a randomized complete block design experiment consisting of 4 treatments. Treatments consisted of diets containing $0,0.003,0.03$, or $0.3 \%$ (diet DM) menthol (Ind-Swift Laboratories Limited, Dover, DE). Composition of the diets are presented in Table 1. Steers were weighed, stratified into weight blocks, and randomly assigned, within block, to individual, partially covered feeding stalls equipped with concrete floors, fence-line feed bunks, and automatic water fountains to allow ad libitum access to feed and water. Individual feeding pens were located within 3 barns (barns A, B, and C) that were located within the same vicinity. The surrounding environment, pen size ( 1.5 by $6 \mathrm{~m}$ ), amount of shade, waterers, and bunk arrangements were identical among barns. Barns A and B contained 20 animals and barn $\mathrm{C}$ contained 12 animals with treatments evenly distributed among barns.
Table 1. Ingredient and nutrient composition of diets fed to Holstein steers supplemented with $0,0.003$, 0.03 , or $0.3 \%$ menthol (diet DM) daily for $30 \mathrm{~d}$

\begin{tabular}{|c|c|c|c|c|}
\hline \multirow[b]{2}{*}{ Item } & \multicolumn{4}{|c|}{ Menthol, \% diet DM } \\
\hline & $0 \%$ & $0.003 \%$ & $0.03 \%$ & $0.3 \%$ \\
\hline \multicolumn{5}{|l|}{ Ingredients } \\
\hline Steam flaked corn & 50.39 & 50.39 & 50.34 & 49.89 \\
\hline Wet corn gluten feed & 33.640 & 33.637 & 33.660 & 33.840 \\
\hline Corn silage & 12.00 & 12.00 & 12.00 & 12.00 \\
\hline Feed additive premix ${ }^{1}$ & 2.16 & 2.16 & 2.16 & 2.16 \\
\hline Vitamin/mineral premix ${ }^{2}$ & 0.07 & 0.07 & 0.07 & 0.07 \\
\hline Limestone & 1.44 & 1.44 & 1.44 & 1.44 \\
\hline Salt & 0.30 & 0.30 & 0.30 & 0.30 \\
\hline Menthol & - & 0.003 & 0.03 & 0.3 \\
\hline \multicolumn{5}{|c|}{ Calculated nutrient composition, ${ }^{3} \%$} \\
\hline $\mathrm{CP}$ & 14.00 & 14.00 & 14.00 & 14.00 \\
\hline $\mathrm{Ca}$ & 0.62 & 0.62 & 0.62 & 0.62 \\
\hline $\mathrm{P}$ & 0.51 & 0.51 & 0.51 & 0.51 \\
\hline $\mathrm{K}$ & 0.70 & 0.70 & 0.70 & 0.70 \\
\hline NDF & 20.08 & 20.08 & 20.08 & 20.10 \\
\hline
\end{tabular}

${ }^{1}$ Formulated to provide $300 \mathrm{mg} / \mathrm{d}$ monensin and $90 \mathrm{mg} / \mathrm{d}$ tylosin (Elanco Animal Health, Greenfield, IN) in a ground corn carrier.

${ }^{2}$ Formulated to provide 2,200 IU/kg vitamin A, $22 \mathrm{IU} / \mathrm{kg}$ vitamin E, $10 \mathrm{mg} / \mathrm{kg}$ added $\mathrm{Cu}, 60 \mathrm{mg} / \mathrm{kg}$ added $\mathrm{Zn}, 60 \mathrm{mg} / \mathrm{kg}$ added $\mathrm{Mn}, 0.5 \mathrm{mg} / \mathrm{kg}$ added $\mathrm{I}, 0.25 \mathrm{mg} / \mathrm{kg}$ added $\mathrm{Se}$, and $0.15 \mathrm{mg} / \mathrm{kg}$ added Co.

${ }^{3}$ Calculated based on NRC (2000) values.

\section{Diet Preparation and Animal Feeding}

Feed intakes were visually monitored and adjusted daily so only trace amounts of residual feed remained the following day. Weights of fresh feed were recorded daily and unconsumed feed was removed from the bunk and weighed on d 16 and 30 before feeding or as needed to determine DMI. Samples of unconsumed feed were dried at $55^{\circ} \mathrm{C}$ for $48 \mathrm{~h}$ to determine actual DMI. Menthol crystals were crushed by hand to ensure adequate distribution in the complete diet. Crushed menthol was weighed daily and incorporated into the preweighed vitamin/trace mineral mix, which was subsequently mixed into complete diets. Diets were mixed once daily and hand delivered to each pen according to the following schedule: Barn A was fed at approximately $1500 \mathrm{~h}$, Barn B was fed at approximately $1600 \mathrm{~h}$, and Barn C was fed at approximately $1700 \mathrm{~h}$ daily. Day 1 as-fed amounts were determined by obtaining the average as-fed intake of steers before study initiation.

\section{Animal Processing and Handling}

Before arrival at the Kansas State University Beef Cattle Research Center (Manhattan, KS), steers received a 5-way viral vaccine (Bovishield Gold 5; Zoetis Animal Health, Florham Park, NJ), a 7-way clostridial vaccine (Vision 7 Somnus; Merck Animal Health, Madison, NJ), a salmonella vaccine (Salmonella 
Newport; Zoetis Animal Health), a metaphalaxis (Micotil; Elanco Animal Health, Greenfield, IN), and a Mannheimia haemolytica toxoid (Presponse SQ; Boehringer Ingelheim Vetmedica, Inc., St. Joseph, MO) and were implanted with Revalor G (40 mg trenbolone acetate and $8 \mathrm{mg}$ estradiol; Merck Animal Health), dewormed with Ivomec pour-on (Merial Inc., Duluth, GA), and tagged with ear tags unique to each animal. Upon arrival, steers were housed in a group setting in dirt-surfaced pens for $11 \mathrm{mo}$ and adapted to a finishing diet before study initiation.

Steers were not previously acclimated to individual pens before study initiation. On d 1 of the experiment, blood samples were obtained via jugular venipuncture at $0,6,12,18$, and $24 \mathrm{~h}$ after feeding. Treatment administration commenced on $\mathrm{d} 2$, and blood samples were again drawn at $0,6,12,18$, and $24 \mathrm{~h}$ after feeding. This blood-sampling schedule was repeated on $\mathrm{d}$ $9,16,23$, and 30 and BW were obtained $\mathrm{h} 0$ on $\mathrm{d} 1$, $9,16,23$, and 30. Blood samples were collected using two 6-mL blood tubes containing EDTA (Vacutainer; Becton, Dickinson and Company, Franklin Lakes, NJ) as an anticoagulant for analysis of glucose, lactate, and PUN. A third tube of blood was collected using 10-mL serum sampling tubes (Vacutainer; Becton, Dickinson and Company) to obtain serum for IGF-1 analysis. Blood samples in tubes containing EDTA were immediately centrifuged at $2,494 \times g$ for $15 \mathrm{~min}$ at room temperature to recover plasma. Plasma was transferred to $5-\mathrm{mL}$ plastic tubes, capped, and frozen at $-20^{\circ} \mathrm{C}$ for subsequent analysis of PUN, glucose, and lactate. Serum samples were allowed to coagulate for $1 \mathrm{~h}$ at $4^{\circ} \mathrm{C}$ and then samples were centrifuged and the serum was collected and stored as described for plasma.

\section{Chemical Analyses}

Glucose and lactate concentrations in plasma were analyzed using the YSI 2300 STAT Plus Glucose and L-Lactate Analyzer (YSI Inc., Yellow Springs, OH). Concentrations of PUN were determined according to the procedure described by Marsh et al. (1965) using the Auto Analyzer II (Seal Analytical, Mequon, WI). Insulin-like glucose factor 1 was measured using the IGF-1 ELISA kit (Immunodiagnostic Systems Inc., Fountain Hills, AZ) and absorbance was measured using the Wallac Victor 21420 Multilabel Counter (PerkinElmer, Inc., Waltham, MA).

\section{In Vitro}

Ruminal fluid was collected from a ruminally fistulated Holstein steer approximately $2 \mathrm{~h}$ before feeding. The diet of the donor steer consisted of $7 \%$ ground brome hay,
$8 \%$ corn steep liquor, $80.2 \%$ steam-flaked corn, $2.16 \%$ feed additive premix, and $2.64 \%$ vitamin/mineral premix. Ruminal fluid was placed directly into prewarmed insulated water jugs to maintain temperature and transported $2 \mathrm{~km}$ to the Pre-Harvest Safety Micro Laboratory on the Kansas State University campus (Manhattan, KS). Ruminal fluid was strained with 4 layers of cheesecloth, placed into separatory funnels, and incubated at $38^{\circ} \mathrm{C}$ for approximately $1 \mathrm{~h}$ to allow ruminal fluid to stratify. The bottom sediment was removed, and $50 \mathrm{~mL}$ of the bacteria-rich middle layer of strained ruminal fluid and $150 \mathrm{~mL}$ of McDougall's buffer (McDougall, 1948) was added to each Ankom fermentation flask (Ankom Technology, Macedon, NY). The substrate used for each fermentation flask consisted of $85 \%$ corn, $5 \%$ soybean meal, and $10 \%$ alfalfa, and the total substrate in each flask was $1 \mathrm{~g}$. The study was conducted as a randomized complete block design with treatments consisting of $0,0.3,0.03$, or $0.003 \%$ menthol. Crystalline menthol was mixed with ethanol to obtain a 3\% menthol solution. The 3\% menthol solution (wt/vol) was diluted with ethanol to equal $0.3,0.03$, or $0.003 \%$ menthol (substrate DM). Ethanol was used for control treatments to maintain constant volume among treatments. Menthol mixtures were added at a rate of 0.1 $\mathrm{mL} /$ flask, with 5 flasks/treatment. Three bottles containing no substrate served as blanks. After all the components were added to the fermentation flasks, bottles were capped with the Ankom pressure module (Ankom Gas Production System; Ankom Technology) and placed into a Precision reciprocal shaking bath (Thermo Electron Corporation, Marietta, $\mathrm{OH}$ ) and maintained at $39^{\circ} \mathrm{C}$ for $24 \mathrm{~h}$. Gas pressure was measured every $5 \mathrm{~min}$. When $24 \mathrm{~h}$ was complete, flasks were removed from the shaker and final $\mathrm{pH}$ was determined using a Thermo Orion benchtop pH meter (model 230 A; Thermo Fisher Scientific Inc., Waltham, MA). Finally, $4 \mathrm{~mL}$ of the flask fluid layer was

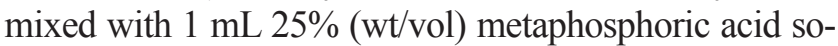
lution and frozen overnight $\left(-20^{\circ} \mathrm{C}\right)$. After thawing, $2 \mathrm{~mL}$ of each mixture were placed into micro centrifuge tubes and centrifuged at $17,000 \times g$ for $10 \mathrm{~min}$ at room temperature. The supernatant was removed, placed into storage vials, and stored in a freezer at $-20^{\circ} \mathrm{C}$ until VFA analysis. Remaining samples in fermentation flasks were placed into 19.0- $\times 12.7-\mathrm{cm}$ aluminum pans and dried for $24 \mathrm{~h}$ at $105^{\circ} \mathrm{C}$ to determine IVDMD. Calculations of IVDMD were as follows: substrate weight - (dry pan weight - initial pan weight - average residue weight of blanks).

\section{Volatile Fatty Acid Analysis}

One milliliter of supernatant was pipetted into $12 \times$ $75 \mathrm{~mm}$ tubes, $50 \mu \mathrm{L}$ of $6 N$ sodium hydroxide was added, and tubes were then vortexed. Pivalic internal standard was added at a rate of $3 \mathrm{~mL} /$ tube and mixed (final pivalic 
acid internal standard concentration was $3 \mathrm{mM}$ ). One milliliter of the mix was transferred to a gas chromatography vial and refrigerated at $4^{\circ} \mathrm{C}$ until analysis. The standard was prepared by weighing $19.2 \mathrm{mg}$ lithium lactate into a $25-\mathrm{mL}$ volumetric flask. The flask was filled to volume with VFA standard. The VFA standard was prepared by adding $3 \mathrm{~g}$ acetate, $0.89 \mathrm{~g}$ propionate, 0.40 $\mathrm{g}$ isobutyrate, $0.88 \mathrm{~g}$ butyrate, $0.41 \mathrm{~g}$ isovalerate, $0.46 \mathrm{~g}$ valerate, and $50 \mathrm{~g}$ meta-phosphoric acid dissolved in 500 $\mathrm{mL}$ deionized water using a $1-\mathrm{L}$ volumetric flask and then brought to $1 \mathrm{~L}$ volume using deionized water. The analysis was performed using an HP 5890 GC (Agilent Technologies, Santa Clara, CA) equipped with a flame ionization detector and a 2-m $\times 2$-mm Carbopak B-DA column (Supelco, Inc., Bellefonte, PA) using nitrogen gas as the carrier. The injection and detector temperature was $200^{\circ} \mathrm{C}$, oven temperature was $175^{\circ} \mathrm{C}$, and flow rate was $24 \mathrm{~mL} / \mathrm{min}$.

\section{Statistical Analyses}

Feedlot performance was analyzed with the MIXED procedure of SAS version 9.3 (SAS Inst. Inc., Cary, NC) using menthol as the fixed effect and weight block as the random effect. Animal was the experimental unit. Blood measurements, BW, and feed fed daily (DM basis) were analyzed as repeated measures using the MIXED procedure of SAS. The repeated measures statement included day with animal nested within treatment as the subject and compound symmetry as the covariance structure. Menthol, day, and menthol $\times$ day were included as fixed effects. The random effect was weight block, and animal was the experimental unit. Plasma and serum measurements collected at $\mathrm{h} 0,6,12,18$, and 24 were averaged by day of collection to determine the effect of day. Day 1 h 0 IGF-1 concentration was used as a covariate for determining the effect of menthol supplementation on IGF-1 concentration due to differences of initial IGF-1 concentration among treatments. Total gas production, VFA, lactate, $\mathrm{pH}$, and IVDMD were analyzed using the MIXED procedure of SAS. The model statement included menthol as the fixed effect and replicate as the random effect. The LSMEANS statement was used for means and SE calculations, and the PDIFF option was used for separation of means. Data were analyzed for effects of menthol supplementation by the orthogonal contrast: $0 \%$ menthol vs. the average of $0.003,0.03$, and $0.3 \%$ menthol and level of menthol supplementation for linear, quadratic, and cubic responses. Separations of means were determined to be significant at an $\alpha$ level $\leq 0.05$ and tendencies at $P>$ 0.05 and $P \leq 0.10$.

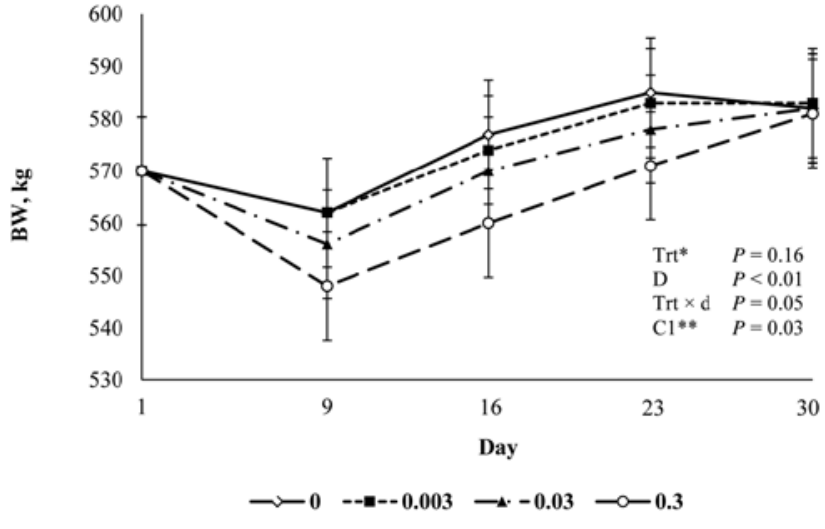

Figure 1. Effect of $0,0.003,0.03$, and $0.3 \%$ diet DM menthol supplementation on BW obtained from Holstein steers before feeding on $\mathrm{d}$ $1,9,16,23$, and 30. Treatment administration commenced on $\mathrm{d} 2$ of the experimental period. *Effect of treatment (Trt). ${ }^{* *}$ A linear response $(\mathrm{C} 1)$ was detected with decreased BW as menthol concentration in the diet increased. No quadratic or cubic effects ( $P=0.44$ and $P=0.93$, respectively) or difference between $0 \%$ menthol vs. the average of the 3 menthol supplementation levels $(P=0.20)$ were detected. $\mathrm{D}$ or $\mathrm{d}=$ day.

\section{RESULTS AND DISCUSSION}

Two animals were removed from the study. One was removed from the $0.003 \%$ menthol group due to a displaced abomasum, and the other was removed from the $0 \%$ menthol group due to a physical injury that required treatment using steroidal anti-inflammatory medications. This resulted in unequal observational units per treatment and an unequal number of treatments/block, which affected the SE for some mean comparisons. No quadratic or cubic responses $(P>0.10)$ or differences between $0 \%$ menthol compared with the average of the menthol treatments $(P>0.20)$ were detected for any response variables and, therefore, will not be discussed.

\section{Growth Performance}

Limited information is available on the effects of menthol supplementation in growing animals, and no studies have been published with respect to its effects on finishing cattle. A treatment $\times$ day interaction $(P=0.05$; Fig. 1$)$ was detected for BW. Steers in the treatment containing $0.3 \%$ menthol had the lightest BW from d 9 to 23 compared with steers receiving 0 or $0.003 \%$ menthol. This contributed to a linear response $(P=0.03)$, in which cattle receiving $0 \%$ menthol had the greatest $\mathrm{BW}$ and cattle receiving $0.3 \%$ menthol had the lightest BW; however, BW measurements on d 1 and 30 were comparable among treatments. In addition, there was no effect of treatment $(P=0.16)$, but an effect of day was detected $(P<0.01)$, with BW differing each day. Soltan (2009) observed a decrease in live BW of dairy calves the first month after weaning when an essential oil mixture containing menthol was 
Table 2. Effects of $0,0.003,0.03,0.3 \%$ menthol supplementation on feedlot performance of Holstein steers fed for $30 \mathrm{~d}$

\begin{tabular}{|c|c|c|c|c|c|c|c|c|c|c|}
\hline \multirow[b]{2}{*}{ Item } & \multicolumn{4}{|c|}{ Menthol, \% diet DM } & \multirow[b]{2}{*}{ SEM } & \multicolumn{5}{|c|}{$P$-value ${ }^{1}$} \\
\hline & 0 & 0.003 & 0.03 & 0.3 & & Trt & $\mathrm{C} 1$ & $\mathrm{C} 2$ & $\mathrm{C} 3$ & $\mathrm{C} 4$ \\
\hline $\mathrm{ADG}, \mathrm{kg} / \mathrm{d}$ & 0.39 & 0.43 & 0.40 & 0.36 & 0.17 & 0.98 & 0.75 & 0.99 & 0.85 & 0.98 \\
\hline DMI, kg/d & 7.52 & 7.51 & 7.81 & 7.03 & 0.36 & 0.25 & 0.08 & 0.31 & 0.91 & 0.82 \\
\hline G:F & 0.0448 & 0.0388 & 0.0457 & 0.0459 & 0.0221 & 0.99 & 0.89 & 0.90 & 0.82 & 0.95 \\
\hline
\end{tabular}

${ }^{1}$ Includes effect of treatment (Trt), linear (C1), quadratic (C2), and cubic (C3) effects of menthol supplementation level and the following orthogonal contrast: $0 \%$ menthol vs. the average of the 3 concentrations of menthol supplementation (C4).

administered at $15.6,31.2$, or $46.8 \mathrm{mg} / \mathrm{L}$ (providing $0,6.2,12.3$, or $18.5 \mathrm{mg}$ menthol/d) in drinking water compared with calves that did not receive the essential oil mixture. These authors also observed an increase in BW during the second and third month after weaning for calves receiving $15.6 \mathrm{mg} / \mathrm{L}$ drinking water compared with control calves, but BW of calves receiving 31.2 and $46.8 \mathrm{mg} / \mathrm{L}$ of essential oil did not differ from the control calves. Toghyani et al. (2010) reported an increase in BW of chicks at $28 \mathrm{~d}$ of age but no difference at $42 \mathrm{~d}$ of age when dried peppermint was added to broiler diets at 4 or $8 \mathrm{~g} / \mathrm{kg}$. Similarly, Al-Kassie (2010) supplemented chicks with $0.25,0.5,1.0$, or $1.5 \%$ dried peppermint and observed an increase in BW for all peppermint-supplemented broilers compared with control broilers. Soltan et al. (2010) administered an essential oil mixture containing menthol by mixing the essential oils in water supplied to dairy cows at rates of 0,16 , 32 , and $48 \mathrm{mg}$ essential oils/L water (supplying $0,1.12$, 2.24 , or $3.36 \mathrm{mg}$ menthol/L water) and observed an increase in BW for cows receiving 16 and $32 \mathrm{mg}$ essential oils/L water compared with either the control cows or cows receiving $48 \mathrm{mg}$ essential oils/ $\mathrm{L}$ water.

Average DMI over the entire 30-d feeding period did not differ $(P=0.25)$ among treatments (Table 2$)$. A tendency for a linear response $(P=0.08)$ was detected, in which cattle supplemented with $0.3 \%$ menthol tended to consume the least amount compared with the cattle in the other treatments. A treatment $\times$ day interaction was observed $(P<0.01)$ for amount of feed fed daily. Steers fed $0.3 \%$ menthol consumed the least from d 5 through 12 , at which point feed delivered to cattle fed $0.3 \%$ menthol was similar to that of the other 3 treatments (Fig. 2). The decreased daily feed deliveries in cattle fed $0.3 \%$ menthol was attributed to the stronger taste and aroma of menthol delivered at $0.3 \%$ of the diet DM compared with that of the other treatments, as evidenced by the dramatic decrease in feed delivered at the initiation of the trial. Steers fed $0.3 \%$ menthol appeared to adapt to the increased aroma and taste of menthol and began to consume amounts equivalent to $0,0.003$, and $0.03 \%$ menthol treatments by $\mathrm{d} 13$ of the experiment. Differences in BW in the current study may be partly attributed to the decreased feeding amounts for steers initially fed $0.3 \%$ menthol compared with other treatments. Soltan et al. (2010) observed a decrease in
DMI when an essential oil mixture (supplying 0, 1.12, 2.24 , or $3.36 \mathrm{mg}$ menthol/L) was added to drinking water of dairy cattle. Soltan (2009) also reported a decrease in intake for weaned dairy calves receiving an essential oil mixture (providing $0,6.2,12.3$, or $18.5 \mathrm{mg}$ menthol/d) the first 2 wk after weaning. Studies performed using broiler chicks reported either no differences in feed intake with the addition of dried peppermint (assumed to provide $70 \mathrm{mg}$ menthol $/ \mathrm{kg}$ diet; Ocak et al., 2008) to the diet (Toghyani et al., 2010) or a decrease with the addition of $1.5 \%$ dried peppermint to the diets of broilers $6 \mathrm{wk}$ of age (Al-Kassie, 2010). Bioactivity of menthol in peppermint depends on plant variety, geographical location, plant maturity, climate, and processing conditions (Gherman et al., 2000) and because of these factors, peppermint can contain 33 to 60\% menthol (Dimandja et al., 2000; Gherman et al., 2000) and peppermint oil can contain up to $85 \%$ menthol. Difficulty arises when comparing studies using peppermint or peppermint oil, as some authors did not indicate the essential oil composition. Feed intakes in the current trial may have been affected by frequent handling of the animals, because steers never consumed amounts equal to daily feed delivered on $\mathrm{d} 1$.

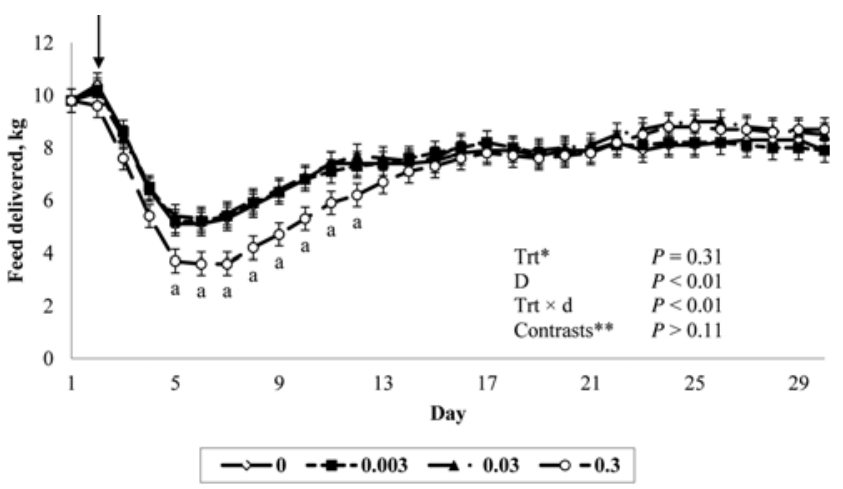

Figure 2. Effect of menthol supplementation on daily feed delivered to Holstein steers (DM basis) for the 30-d experimental period. Diets were formulated to contain $0,0.003,0.03$, and $0.3 \%$ diet DM menthol. Bunks were monitored and adjusted daily so less than $0.22 \mathrm{~kg}$ residual feed remained the following day. Feed delivered daily was recorded on an as-fed basis and then converted to DM based on individual ingredient DM analyses. Day 1 feed delivered was determined based on average consumption before study initiation. The arrow indicates beginning of treatment administration $(\mathrm{d} 2)$. *Effect of treatment (Trt). **No linear, quadratic, or cubic effects $(P=0.11$, $P=0.36$, and $P=0.97$, respectively). There was no difference when $0 \%$ menthol was compared with the average of the 3 menthol treatments $(P=$ 0.86). ${ }^{\text {a }}$ Data points indicate cattle assigned to the $0.3 \%$ menthol treatment consumed less feed than the other 3 treatments $(P<0.05)$. D or $\mathrm{d}=$ day. 


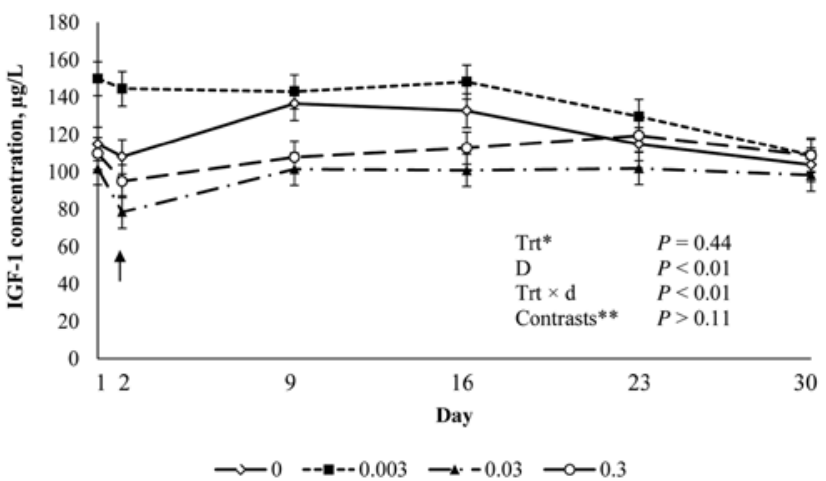

Figure 3. Effect of $0,0.003,0.03$, and $0.3 \%$ diet DM menthol supplementation on serum IGF-1 concentration from Holstein steers. Blood was collected on $\mathrm{d} 1,2,9,16,23$, and 30 at h $0,6,12,18$, and 24 after feeding via jugular venipuncture. Averages were calculated from hour collection periods to determine day IGF-1 concentration. The arrow indicates beginning of treatment administration (d 2 of feeding period). *Effect of treatment (Trt). ${ }^{*}$ No linear, quadratic, or cubic effects $(P=0.80, P=0.11$, and $P=0.81$, respectively). No difference was detected when $0 \%$ menthol was compared with the average of the 3 menthol treatments $(P=0.27)$. D or $\mathrm{d}=$ day

Average daily gain and feed efficiency were unaffected $(P>0.98$; Table 2$)$ by addition of menthol to diets of steers. No linear responses were observed for level of menthol supplementation for ADG or G:F $(P>$ 0.75). In agreement, Ocak et al. (2008) and Toghyani et al. (2010) reported no differences in gain or efficiency for broilers supplemented with dried peppermint. Soltan (2009) observed no effect on ADG or feed efficiency in dairy calves when a menthol mixture (providing 0 , $6.2,12.3$, or $18.5 \mathrm{mg}$ menthol/d) was added to drinking water. Contradicting the current results, Maenner et al. (2011) fed $300 \mathrm{mg} / \mathrm{kg}$ DM of essential oil mixture containing $27.8 \mathrm{~g}$ anise oil, $12.5 \mathrm{~g}$ clove oil, and $46.0 \mathrm{~g}$ peppermint oil $/ \mathrm{kg}$ of additive or $4.44 \mathrm{~g}$ anise oil, $1.3 \mathrm{~g}$ clove oil, and $2.0 \mathrm{~g}$ cinnamon oil $/ \mathrm{kg}$ of additive to piglets after weaning. Live performance and ileal digestibility were recorded. The authors observed no improvement in ADG, but G:F was greater for piglets supplemented with peppermint oil mixture, and they attributed improvements in G:F to increased ileal digestibility of $\mathrm{CP}$ and AA. Overall, the lack of differences in animal performance in the current study may be explained by the ability of menthol to affect growth in younger animals by increasing digestion, but as animals age, the effect is no longer observed (Toghyani et al., 2010).

\section{Blood Parameters}

The main purpose of this experiment was to assess changes within blood metabolites related to growth. Insulin-like growth factor 1 has an important role in the growth of developing animals due to its impact on cell growth, proliferation, and metabolism (Micke et al.,

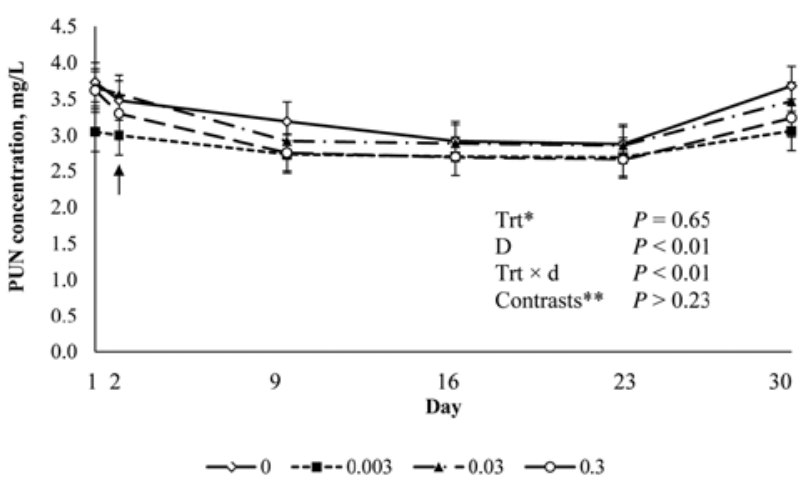

Figure 4. Effect of $0,0.003,0.03$, and $0.3 \%$ diet DM menthol supplementation on plasma urea nitrogen (PUN) concentration from Holstein steers. Blood was collected on d 1, 2, 9, 16, 23, and 30 and at h 0, 6, 12, 18, and 24 after feeding via jugular venipuncture. Averages were calculated from hour collection periods to determine day PUN concentration. The arrow indicates beginning of treatment administration on $\mathrm{d} 2$ of feeding. *Effect of treatment (Trt). **No linear, quadratic, or cubic effects $(P=$ $0.78, P=0.74$, and $P=0.23$, respectively). There was no difference when $0 \%$ menthol supplementation was compared with the average of the 3 menthol treatments $(P=0.39)$. D or $\mathrm{d}=$ day.

2010). A treatment $\times$ day interaction $(P<0.01$; Fig. 3$)$ was observed for IGF-1 concentration with the addition of menthol to the diets of steers. Animals fed $0.03 \%$ menthol had decreased IGF-1 concentration on $\mathrm{d} 2$ compared with animals supplemented with 0 or $0.003 \%$ menthol $(P \leq 0.04)$. Steers supplemented with 0.03 and $0.3 \%$ menthol had decreased IGF-1 compared with steers receiving $0 \%$ menthol $(P \leq 0.03)$ on $\mathrm{d} 9$, whereas on d 16, only steers supplemented with $0.03 \%$ menthol had decreased IGF-1 compared with nonsupplemented steers $(P=0.02)$. After d 23, IGF-1 concentrations were comparable among all 4 treatments $(P>0.05)$. Treatments containing 0.03 or $0.3 \%$ menthol were not different among sampling day $(P>0.05)$. There were no treatment or linear effects $(P>0.11)$ detected for serum IGF-1 concentration, but an effect of day was detected $(P<0.01)$. To the authors' knowledge, IGF1 concentrations with menthol supplementation have not been reported in other published experiments, making it difficult to extrapolate and compare information. Increased concentrations of menthol may reduce IGF-1 concentration when first introduced into diets of finishing cattle; however, due to the dramatic decrease in intake at trial initiation, it is difficult to determine whether differences were due to menthol or to changes in metabolism from decreased intake.

Plasma urea nitrogen concentration can be used as an indicator of muscle growth or protein degradation. A treatment $\times$ day interaction $(P<0.01$; Fig. 4$)$ was detected for PUN concentration. There were no differences among treatments each day of sampling, but PUN concentrations decreased for all treatments following treatment administration on d 2 . On d 30, steers supplement- 


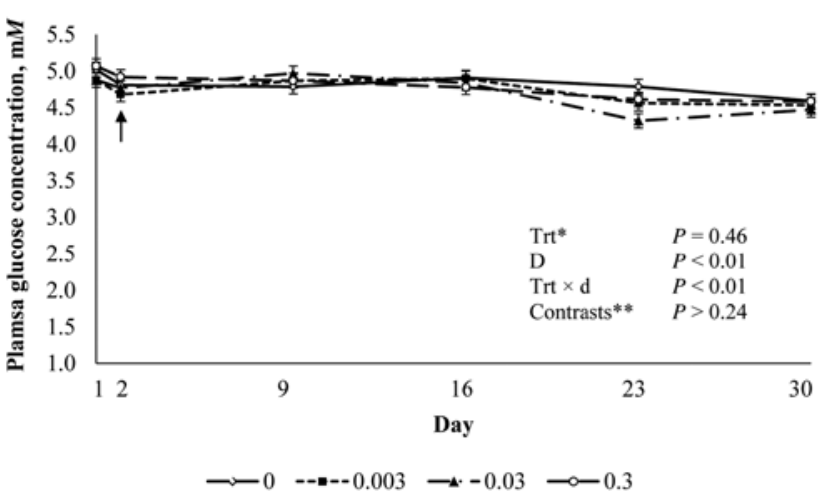

Figure 5. Effect of 0, 0.003, 0.03, and 0.3\% diet DM menthol supplementation on plasma glucose concentration. Blood samples were obtained from 50 Holstein steers on d 1, 2, 9, 16, 23, and 30 at h 0, 6, 12, 18, and 24 after feeding via jugular venipuncture. Averages were calculated from hour collection periods to determine day plasma glucose concentration. The arrow indicates beginning of treatment administration on $2 \mathrm{~d}$ of feeding. *Effect of treatment (Trt). **No linear, quadratic, or cubic responses $(P=0.54, P=0.24$, and $P=0.37$, respectively). No difference was detected when $0 \%$ menthol was compared with the average of the 3 menthol treatments $(P=0.29)$. D or d $=$ day.

ed with 0.03 and $0.3 \%$ menthol still had decreased PUN concentrations compared with d 1 concentrations $(P<$ 0.05 ), whereas steers supplemented with 0 or $0.003 \%$ menthol had PUN concentrations on d 30 comparable with $\mathrm{d} 1$ concentrations $(P<0.05)$. No effect of treatment $(P=0.65)$ or linear response $(P=0.78)$ was observed for plasma PUN concentrations, but an effect of day $(P<$ 0.01) was detected, with PUN measurements being different each day. To the authors' knowledge, no published data reports the effects of menthol on PUN concentrations. The lack of differences observed in PUN concentrations suggests that nitrogen metabolism is not affected by the addition of menthol to diets of cattle.

Glucose and lactate concentrations are associated with carbohydrate and lipid metabolism and are important components of cellular metabolism. A treatment $\times$ day interaction was detected for plasma glucose concentration $(P<0.01$; Fig. 5). Treatments were not different until d 23, when cattle supplemented with $0.03 \%$ menthol had a decreased plasma glucose concentration compared with cattle supplemented with $0,0.003$, and $0.3 \%$ menthol $(P<0.05)$. No differences were observed among treatments on d $30(P>0.05)$. In addition, all plasma glucose concentrations were lower on d 23 and 30 compared with $\mathrm{d} 1$ concentrations $(P<0.05)$. No treatment $\times$ day interaction was observed for plasma lactate concentration ( $P=0.99$; Fig. 6). An effect of day was detected for both plasma glucose and lactate $(P<0.01)$. No effect of treatment or linear effects were detected $(P>0.28)$. Conversely, Soltan (2009) measured serum glucose of calves administered an essential oil mixture through their milk replacer and observed a $26.4 \%$ increase in serum glucose concentration in calves receiving $281 \mathrm{mg} / \mathrm{d}(18.5$

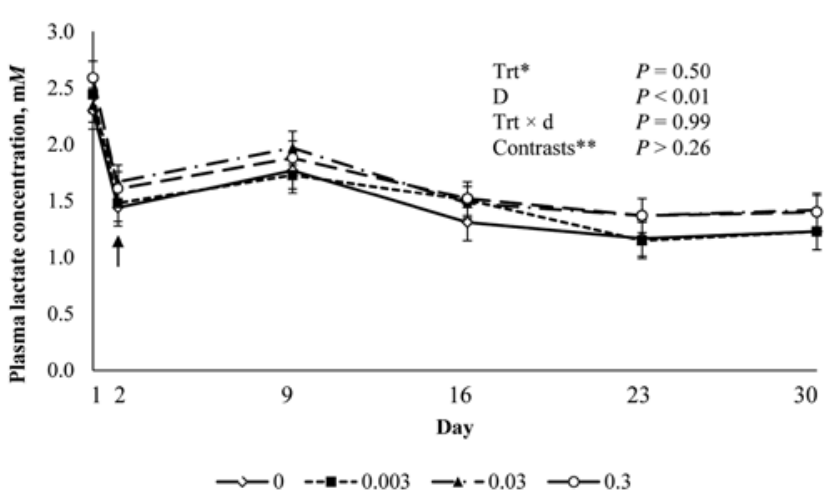

Figure 6. Effect of $0,0.003,0.03$, and $0.3 \%$ diet DM menthol supplementation on plasma lactate concentration. Blood was obtained from Holstein steers on $\mathrm{d} 1,2,9,16,23$, and 30 at h $0,6,12,18$, and 24 after feeding via jugular venipuncture. Averages were calculated from hour collection periods to determine day plasma glucose concentration. The arrow indicates beginning of treatment administration on $\mathrm{d} 2$ of feeding. *Effect of treatment (Trt). **No linear, quadratic, or cubic responses $(P=0.28, P=0.28$, and $P=0.80$, respectively). No difference was detected when $0 \%$ menthol was compared with the average of the 3 menthol treatments $(P=0.26)$. D or $\mathrm{d}=$ day.

$\mathrm{g} / \mathrm{d}$ menthol) compared with control calves. The differences observed between the current study and that of Soltan (2009) may be due to age differences of animals or route of administration. Menthol administered as a liquid may be absorbed more quickly than if it were fed in a ration, potentially explaining why calves in the Soltan study had increased glucose values whereas steers in the current trial fed $0.003 \%$ menthol did not. Huntington et al. (1980) indicated the diet and rumen fermentation are sources of lactate entering the blood; therefore, the decrease in plasma lactate from $\mathrm{d} 2$ to 30 may be reflective of the decreased intake observed during the experimental period compared with intakes on $\mathrm{d} 1$.

In summary, menthol did not affect serum IGF-1, PUN, glucose, or lactate concentrations. The interactions observed for IGF-1, PUN, and glucose concentrations may have been influenced more by differences due to the day effect rather than by menthol supplementation, as no effects of treatment were detected for any blood metabolite measured. The dramatic drop in intake at trial initiation may have resulted in unforeseen effects on blood metabolites due to metabolic changes that may have occurred in the first $13 \mathrm{~d}$ before cattle maintained consistent intakes.

\section{In Vitro}

In vitro results are presented in Table 3. Menthol, administered to cattle in the form of peppermint, has consistently demonstrated decreased methane production (Agarwal et al., 2009; Zmora et al., 2012), which may influence the total amount of ruminal gas produced. Menthol supplementation did not affect fermentative 
Table 3. Effects of adding $0,0.003,0.03,0.3 \%$ (substrate $\mathrm{DM}$ ) menthol ${ }^{1}$ to fermentation flasks containing $50 \mathrm{~mL}^{\mathrm{rumi}}$ nal fluid, $150 \mathrm{~mL}$ McDougal's buffer, and $1 \mathrm{~g}$ substrate $^{2}$ on gas production, $\mathrm{pH}$, IVDMD, lactate, and VFA production following $24 \mathrm{~h}$ of fermentation using an Ankom Gas Production System (Ankom Technology, Macedon, NY)

\begin{tabular}{|c|c|c|c|c|c|c|c|c|c|c|}
\hline \multirow[b]{2}{*}{ Item } & \multicolumn{4}{|c|}{ Menthol, \% substrate DM } & \multirow[b]{2}{*}{ SEM } & \multicolumn{5}{|c|}{$P$-value ${ }^{3}$} \\
\hline & 0 & 0.003 & 0.03 & 0.3 & & Trt & $\mathrm{C} 1$ & $\mathrm{C} 2$ & $\mathrm{C} 3$ & $\mathrm{C} 4$ \\
\hline Gas production, ${ }^{4} \mathrm{~mL}$ & 182.5 & 180.3 & 177.4 & 176.7 & 2.90 & 0.45 & 0.78 & 0.15 & 0.61 & 0.21 \\
\hline $\mathrm{pH}$ & 6.28 & 6.22 & 6.28 & 6.29 & 0.03 & 0.21 & 0.21 & 0.55 & 0.10 & 0.61 \\
\hline IVDMD, $\mathrm{g}$ & 0.737 & 0.715 & 0.723 & 0.703 & 0.023 & 0.77 & 0.42 & 0.93 & 0.53 & 0.40 \\
\hline Lactate, $\mathrm{m} M$ & 0.06 & 0.05 & 0.20 & 0.25 & 0.10 & 0.34 & 0.16 & 0.26 & 0.83 & 0.33 \\
\hline \multicolumn{11}{|l|}{ VFA, $\mathrm{m} M$} \\
\hline Acetate & 51.04 & 49.98 & 51.06 & 51.55 & 0.88 & 0.65 & 0.40 & 0.74 & 0.39 & 0.87 \\
\hline Propionate & 18.36 & 17.81 & 18.49 & 18.55 & 0.35 & 0.41 & 0.36 & 0.45 & 0.23 & 0.84 \\
\hline Butyrate & 10.10 & 10.08 & 10.20 & 10.18 & 0.18 & 0.95 & 0.76 & 0.63 & 0.90 & 0.79 \\
\hline Isobutyrate & 1.04 & 1.01 & 1.05 & 1.05 & 0.02 & 0.69 & 0.59 & 0.58 & 0.37 & 0.84 \\
\hline 2-Methyl isovalerate & 4.22 & 4.20 & 4.19 & 4.26 & 0.10 & 0.96 & 0.65 & 0.82 & 0.85 & 0.93 \\
\hline 3-Methyl isovalerate & 1.43 & 1.40 & 1.44 & 1.43 & 0.03 & 0.78 & 0.91 & 0.57 & 0.41 & 0.77 \\
\hline Valerate & 1.89 & 1.87 & 1.92 & 1.90 & 0.04 & 0.79 & 0.73 & 0.42 & 0.65 & 0.84 \\
\hline \multicolumn{11}{|c|}{$\begin{array}{l}{ }^{1} \mathrm{~A} 3 \% \text { menthol solution }(\mathrm{wt} / \mathrm{vol}) \text { was diluted with ethanol to equal } 0.3,0.03 \text {, or } 0.003 \% \text { menthol (substrate DM). Ethanol was used for control treatments } \\
\text { to maintain constant volume among treatments. Menthol mixtures were added at a rate of } 0.1 \mathrm{~mL} / \mathrm{flask} \text {, with } 5 \text { flasks/treatment. }\end{array}$} \\
\hline \multicolumn{11}{|c|}{${ }^{2}$ Substrate used for each fermentation flask consisted of $85 \%$ corn, $5 \%$ soybean meal, and $10 \%$ alfalfa. } \\
\hline \multicolumn{11}{|c|}{$\begin{array}{l}{ }^{3} \text { Includes effect of treatment (Trt), linear }(\mathrm{C} 1) \text {, quadratic }(\mathrm{C} 2) \text {, and cubic }(\mathrm{C} 3) \text { effects of menthol supplementation level and the following orthogonal } \\
\text { contrast: } 0 \% \text { menthol vs. the average of the } 3 \text { concentrations of menthol supplementation }(\mathrm{C} 4) \text {. }\end{array}$} \\
\hline
\end{tabular}

gas production $(P=0.45)$ in the current experiment. No linear response was detected for menthol supplementation level $(P=0.78)$. Agarwal et al. (2009) observed an increase in total gas production with the addition of 0.33 and $1.0 \mu \mathrm{L} / \mathrm{mL}$ peppermint oil in vitro, whereas $2.0 \mu \mathrm{L} /$ $\mathrm{mL}$ peppermint resulted in no difference in total gas produced by ruminal microflora. Jani et al. (2010) performed a study in which gas production was measured in vitro using rumen fluid from 2 cannulated sheep. Peppermint oil was added at 14 or $40 \mu \mathrm{L} / \mathrm{g}$ DM to ruminal inoculum and gas measurements were recorded. The authors observed a decrease in the volume of gas produced. The concentration of menthol used in the current experiment is lower than approximate menthol concentrations in previous experiments, which may explain the lack of differences. The current results suggest that $0.003,0.03$, or $0.3 \%$ menthol did not affect ruminal gas production of a microbial population obtained from a donor animal consuming a high-concentrate diet.

Menthol is an essential oil that has been observed to have antibacterial activity and may affect fermentation products of ruminal microorganisms (Eccles, 1994). Menthol had no effect on in vitro concentrations of acetate, propionate, butyrate, isobutyrate, 2- and 3-methyl isovalerate, valerate, or lactate $(P>$ $0.41)$, indicating that menthol had no effect on rumen fermentation. In addition, no linear response of menthol supplementation level was detected $(P>0.36)$ for VFA or lactate concentrations. Hosoda et al. (2005) conducted an in vivo experiment that administered 0 or $5 \%$ peppermint (DM basis) to Holstein cows and orally collected ruminal fluid. In agreement with the current study, the authors reported no difference in total VFA concentration or molar proportion of acetate, propionate, and butyrate among treatments. In contrast, Agarwal et al. (2009) reported a linear increase in the molar proportion of acetate and a linear decrease in the molar proportion of propionate when cultures of mixed ruminal microbes were supplemented with $0,0.33,1$, or $2 \mu \mathrm{L} / \mathrm{mL}$ peppermint oil. A quadratic effect for molar proportion of butyrate was observed, with cultures containing $1 \mu \mathrm{L} / \mathrm{mL}$ peppermint oil having the greatest butyrate concentration and those containing 0 or $2 \mu \mathrm{L} /$ $\mathrm{mL}$ having the least concentration. The authors speculated that differences in VFA concentrations were due to accumulation of molecular hydrogen as a result of decreased methanogenesis. Ando et al. (2003) observed a decrease in propionate concentration in ruminal fluid from cannulated Holstein steers that received $200 \mathrm{~g}$ dried peppermint daily compared with no peppermint supplementation. The authors postulated that the antimicrobial effects of menthol may have had an adverse effect on ruminal fermentation, thereby decreasing VFA production. Lack of congruence among studies may be due to differences in the initial diet of the donor animal, potentially resulting in different microfloral populations in ruminal fluid, in addition to concentration differences of menthol in dried peppermint and peppermint oil. Furthermore, previous experiments administered a greater concentration of menthol than what was used in the current experiment. 
Terminal $\mathrm{pH}$ and IVDMD did not differ among treatments $(P>0.21)$; neither was a linear response of menthol level detected $(P>0.21)$. In agreement, Zmora et al. (2012) observed no differences among treatments for $\mathrm{pH}$ and IVDMD $(P>0.05)$ when dried Mentha piperita L. leaves were added at rates of $2.33,8.17$, 16.34 , or $23.35 \mathrm{mg}$ to batch fermentation incubation vessels. In contrast, Agarwal et al. (2009) observed a quadratic decrease in in vitro true digestibility (IVTD) of feed with the addition of $0.33,1.0$, or $2.0 \mu \mathrm{L} / \mathrm{mL}$ peppermint oil to buffalo rumen liquor, with $1.0 \mu \mathrm{L} / \mathrm{mL}$ peppermint having the greatest decrease in IVTD. In addition, Ando et al. (2003) observed a decrease in rumen $\mathrm{pH}$ with the addition of $200 \mathrm{mg}$ dried peppermint to the diet of cannulated steers. Differences observed among studies may reflect the differences in source of menthol, time of sampling, or diet of donor animals.

In conclusion, addition of menthol to diets of finishing cattle had little or no effect on blood metabolites measured in this trial. The levels of menthol used in the in vitro experiment did not alter rumen microbial fermentation or gas production, suggesting these levels had minimal effects on the microbial population from an animal consuming a high-concentrate ration.

\section{LITERATURE CITED}

Agarwal, N., C. Shekkar, R. Kumar, L. C. Chaudhary, and D. N. Kamra. 2009. Effect of peppermint (Mentha piperita) oil on in vitro methanogenesis and fermentation of feed with buffalo rumen liquor. Anim. Feed Sci. Technol. 148(2-4):321-327. doi:10.1016/j.anifeedsci.2008.04.004.

Al-Kassie, G. A. M. 2010. The role of peppermint (Mentha piperita) on performance in broiler diets. Agric. Biol. J. North Am. 1(5):1009-1013. doi:10.5251/abjna.2010.1.5.1009.1013.

Ando, S., T. Nishida, M. Ishida, K. Hosoda, and E. Bayaru. 2003. Effect of peppermint feeding on the digestibility, ruminal fermentation and protozoa. Livest. Prod. Sci. 82(2-3):245-248. doi:10.1016/S0301-6226(03)00012-5.

Dimandja, J. M. D., S. Stanfill, J. Grainger, and D. G. Patterson Jr. 2000. Application of comprehensive two-dimensional gas chromatography $(\mathrm{GC} \times \mathrm{GC})$ to the qualitative analysis of essential oils. J. High Resolut. Chromatogr. 23(3):208-214. doi:10.1002/(SICI)15214168(20000301)23:3<208::AID-JHRC208>3.0.CO;2-I.

Eccles, R. 1994. Menthol and related cooling compounds. J. Pharm. Pharmacol. 46(8):618-630. doi:10.1111/j.2042-7158.1994. tb03871.x.

Galeotti, N., L. Di Cesare Mannelli, G. Mazzanti, A. Bartolini, and C. Ghelardini. 2002. Menthol: A natural analgesic compound. Neurosci. Lett. Suppl. 322(3):145-148. doi:10.1016/S03043940(01)02527-7.

Gherman, C., M. Culea, and O. Cozar. 2000. Comparative analysis of some active principles of herb plants by GC/MS. Talanta 53(1):253-262. doi:10.1016/S0039-9140(00)00458-6.
Hosoda, K., T. Nishida, W.-Y. Park, and B. Eruden. 2005. Influence of Mentha piperita L. (peppermint) supplementation on nutrient digestibility and energy metabolism in lactating dairy cows. Asian-Australas. J. Anim. Sci. 18:1721-1726.

Huntington, G. B., R. L. Prior, and R. A. Britton. 1980. Glucose and lactate absorption and metabolic interrelationships in lambs switched from low to high concentrate diets. J. Nutr. 110:1904-1913.

Işcan, G., N. Kirimer, M. Kürkcüoğlu, K. H. Başer, and F. Demirci. 2002. Antimicrobial screening of Mentha piperita essential oils. J. Agric. Food Chem. 50(14):3943-3946. doi:10.1021/jf011476k.

Jani, E., M. Danesh Mesgaran, A. R. Vakili, A. Soleimani, and H. Jahani-Azizabadi. 2010. Effect of peppermint (Mentha piperita) essential oil on in vitro gas production parameters of lucerne hay and cottonseed hulls. Adv. Anim. Biosci. 1(01):264. doi:10.1017/S2040470010004073.

Maenner, K., W. Vahjen, and O. Simon. 2011. Studies on the effects of essential-oil-based feed additives on performance, ileal nutrient digestibility, and selected bacterial groups in the gastrointestinal tract of piglets. J. Anim. Sci. 89(7):21062112. doi:10.2527/jas.2010-2950.

Marsh, W. H., B. Fingerhut, and H. Miller. 1965. Automated and manual direct methods for the determination of blood urea. Clin. Chem. 11:624-627.

McDougall, E. I. 1948. Studies on the ruminant saliva. I. The composition and output of sheep's saliva. Biochem. J. 43(1):99109. doi:10.1042/bj0430099.

Meng, F., G. Xie, R. C. Thompson, A. Mansour, A. Goldstein, S. J. Watson, and H. Akil. 1993. Cloning and pharmacological characterization of a rat kappa opioid receptor. Proc. Natl. Acad. Sci. USA 90(21):9954-9958. doi:10.1073/pnas.90.21.9954.

Micke, G. C., T. M. Sullivan, K. L. Gatford, J. A. Owens, and V. E. A. Perry. 2010. Nutrient intake in the bovine during early and mid-gestation causes sex-specific changes in progeny plasma IGF-I, liveweight, height and carcass traits. Anim. Reprod. Sci. 121(3-4):208-217. doi:10.1016/j.anireprosci.2010.05.017.

NRC. 2000. Nutrient requirements of beef cattle. 7 th rev. ed. Natl. Acad. Press, Washington, DC.

Ocak, N., G. Erener, F. Burak Ak, M. Sungu, A. Altop, and A. Ozmen. 2008. Performance of broilers fed diets supplemented with dry peppermint (Mentha piperita L.) or thyme (Thymus vulgaris L.) leaves as growth promoter source. Czech J. Anim. Sci. 53:169-175.

Soltan, M. A. 2009. Effect of essential oils supplemented on growth performance, nutrient digestibility, health condition of Holstein male calves during pre- and post-weaning periods. Pak. J. Nutr. 8(5):642-652. doi:10.3923/pjn.2009.642.652.

Soltan, M. A. E.-K., R. S. Shewita, and S. I. Al-Sultan. 2010. Influence of essential oils supplementation on digestion, rumen fermentation, rumen microbial populations and productive performance of dairy cows. Asian J. Anim. Sci. 4:197208. doi:10.3923/ajas.2009.1.12.

Toghyani, M., M. Toghyani, and A. Gheisari. 2010. Growth performance, serum biochemistry and blood hematology of broiler chicks fed different levels of black seed (Nigella sativa) and peppermint (Mentha piperita). Livest. Sci. 129(1-3):173178. doi:10.1016/j.livsci.2010.01.021.

Zmora, P., A. Cieslak, E. Pers-Kamczyc, A. Nowak, J. Szczechowiak, and M. Szumacher-Strabel. 2012. Effect of Mentha piperita L. on in vitro rumen methanogenesis and fermentation. Acta Agric. Scand., Sect. A 62:46-52. doi:10.1 080/09064702.2012.703228. 